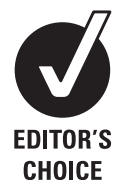

${ }^{1}$ Optometry Department, Oxford Eye Hospital, Oxford, UK ${ }^{2}$ Department of Optometry and Vision Sciences, City University, London, UK

\section{Correspondence to}

Miss Rasmeet K Chadha, Optometry Department, Oxford Eye Hospital, West Wing (LG1). John Radcliffe Hospital, Headley Way, Oxford OX3 9DU, UK; rasmeet11@hotmail.com

Accepted 18 July 2010 Published Online First 18 September 2010

\title{
The effect of visual impairment on quality of life of children aged $3-16$ years
}

\author{
Rasmeet K Chadha, ${ }^{1}$ Ahalya Subramanian ${ }^{2}$
}

\section{ABSTRACT}

Background It is well known that visual impairment (VI) has a detrimental effect on Quality of Life (OoL) in adults. Little is known about the effects of $\mathrm{VI}$ in childhood.

Aims To evaluate the effects of VI on OoL of children. To the authors' knowledge, this is the first study containing a comparison arm for children with $\mathrm{VI}$.

Methods OoL in children with VI $(n=24$, age $10.13 \pm 2.89$, 18 male, 6 female) was compared with an age-matched comparison group $(n=24$, age 9.83 $2.81,18$ male, 6 female) using the Low Vision Quality of Life Questionnaire. Factors (distance and near visual acuity and age) that could be used as predictors of OoL were assessed. These were measured with standard clinical tests.

Results Children with VI had significantly lower OoL scores than the comparison group $(p<0.001)$, resulting in a $35.6 \%$ reduction in total $\mathrm{OoL}$ score. OoL scores in children with VI were correlated with distance and near visual acuity $(p<0.05)$. 38\% of the variance could be predicted by these factors and age.

Conclusions Consideration of the effects of this reduced OoL must be made. Further studies are needed to establish the benefit to $\mathrm{OoL}$ of different habilitation strategies.

\section{INTRODUCTION}

Visual impairment (VI) in childhood has lifelong implications for both the child and their family. Indeed, it affects the child's development, education, and the care given by families and professionals. It also shapes the adult the child will become, affecting employment and social prospects. ${ }^{1}$ Although less common than VI in adulthood, ${ }^{2}$ the number of 'blind years' experienced by these children in their lifetime is of particular significance. ${ }^{3}$ The enduring needs of these children, their parents and families should be considered from a lifelong perspective. ${ }^{4}$

There are no consistent national estimates on the prevalence of childhood VI, as the methods to record prevalence vary between surveys. ${ }^{5}$ Certification in England, completed on a Certificate of Visual Impairment, is as Sight Impaired (Partially sighted) or Severely Sight Impaired (Blind). Using the most recent registration data from 2006, there were approximately 3825 children (0-17 years) registered severely sight impaired and 4800 children registered sight impaired. ${ }^{6}$ The aetiology of childhood VI in the UK is changing, demonstrating a decrease in isolated VI and increase in VI with coexisting neurological disability. ${ }^{7}$

It is important to appreciate that the impact of childhood VI is different to VI in adulthood. It differs not only in terms of age of onset and cause of impairment but perhaps more importantly in terms of the lifetime of disability these children endure and the impact that their VI has on family, friends and relationships as they grow up. In addition, childhood VI poses particular, and distinct, assessment and management challenges to professionals. ${ }^{3}$ Children with VI cannot be considered to be scaled-down adults, and therefore the outcomes of studies relating to Quality of Life (QoL) in adults with VI cannot be extended to relate to childhood VI. Furthermore, while adult standards exist for low-vision services, ${ }^{8} 9$ it is impossible and inappropriate to benchmark paediatric services against these.

It has been estimated that $80 \%$ of education is provided through sight. ${ }^{10}$ The majority of children with VI in the UK are educated in the mainstream setting alongside normally sighted peers ${ }^{11}$ and are encouraged to be integral members of society. It is therefore important to look at their QoL relative to their sighted peers.

There are very few studies on QoL in children with VI. ${ }^{12-14}$ While providing valuable information in a field where very little is currently known, they have been limited by the lack of availability of child-specific vision-related $\mathrm{QoL}$ questionnaires at the time of their study. The studies to date have concentrated on comparing QoL in children with VI with children with other disease. They have not compared QoL of children with VI to normally sighted children without any disability.

There have been some recent developments in the design of children's vision QoL questionnaires: the Children's Visual Function Questionnaire (CVFQ), ${ }^{15}$ LV Prasad Functional Vision Questionnaire (LVP-FVQ) ${ }^{16}$ and The Impact of Visual Impairment on Children (IVI C). ${ }^{17}$ The IVI C was unpublished at the time of this study and, to the author's knowledge, is not available for general use. The LVP-FVO and CVFO were inappropriate for use in this study. The LVP-FVQ was designed in India as a screening tool for developing countries, and so the specificity of the questions to the given cultural group made it difficult to use in the Western population. The CVFO was designed for use by proxies for children up to the age of 7 and has been shown to demonstrate meaningful differences in children with varying levels of VI. ${ }^{18}$ The children in the current study were between the ages of 3 and 16 .

\section{AIMS}

To our knowledge, this is the first study to contain a comparison arm for children with VI in the UK allowing us to relate the effects of their impairment to the society in which they live by asking two questions: 
1. Is there a statistical difference in QoL in children with VI compared with an age-matched comparison group?

2. Are there any demographic or clinical factors that can be used as correlates or predictors of QoL for children with VI?

\section{MATERIALS AND METHODS \\ Participants}

The children were divided into two groups.

\section{Children with VI}

These were regular attendees of the paediatric low vision clinic at Oxford Eye Hospital and had been given a diagnosis/working diagnosis of the aetiology of their VI.

These children received comprehensive visual rehabilitation (now often referred to, and more correctly, as habilitation) and had access to ophthalmic and community support provided by a complement of multidisciplinary professionals working together, centred around the needs of the child and family. Services included investigative tests, formal diagnosis (where possible), emotional support, genetic counselling, low vision assessment, mobility training, and support at home and in school.

\section{Age-matched comparison group}

These attended either the paediatric orthoptic (for investigation and management of a binocular vision anomaly, eg, unilateral amblyopia) or colour vision (for investigation of a suspected congenital colour vision defect) clinic at Oxford Eye Hospital. Thus, they were matched for hospital attendance but had no known visual disability. They were asymptomatic and not undergoing any form of non-optical treatment (eg, patching or surgery) at the time of participation.

\section{Eligibility criteria}

Children with VI had a visual acuity (VA) in their better eye of $\leq \log$ MAR 0.30 .

Children in the age-matched comparison group had a VA in their better eye of $\geq \log$ MAR 0.00 .

In both groups, children with a significant non-visual physical or learning difficulty were excluded.

\section{Outcomes}

The outcomes followed the tenets of the declaration of Helsinki, and informed consent was obtained for all. NHS ethics approval was granted in December 2006.

The Low Vision Quality of Life Questionnaire (LVOOL) ${ }^{19}$ was chosen as the outcome measure for this study. The maximum score is 125 with a higher value reflecting a better QoL score. Of the available vision-specific QoL questionnaires (excluding the paediatric versions for reasons described above) it was most suited to use with children (there are no questions that related solely to an adult population) and was quick to complete (improving response rates).

QoL scores of children in both groups were compared, and correlates and predictors of QoL were investigated for children with VI. Parents were asked to complete the questionnaire but to involve their child to a level appropriate for the individual child. Hence, the questionnaire was primarily completed by proxy.

\section{Statistical analysis}

Sample sizes were calculated using a web-based tool (http:// home.clara.net/sisa/sampshlp.htm). Assuming the data to be normally distributed and to have means and variances attributed to the data collected from patients with VI and the age-matched comparison group used to trial the LVOOL, ${ }^{19}$ the minimum sample size in each group to give $90 \%$ power to detect a difference between the groups at a confidence level of $p=0.001$ for an independent $t$ test was 25 , and using $p=0.05$ with a power of $90 \%$ the sample size was 13 . Using the values for means and $\mathrm{SDs}$ obtained in this study, the sample size required to give a power of $90 \%$ at a confidence level of $p=0.001$ is 12 . Therefore, the sample size in the study $(\mathrm{n}=24)$ allows for conclusions with a power of $90 \%$ and a confidence level of $\mathrm{p}=0.001$ to be made.

Correlation and multiple linear regression were used to look at the relationship between QoL and factors of visual function in children with VI.

Data for children with VI were compared with children in the age-matched comparison group using an independent samples $t$ test.

\section{RESULTS}

\section{Patient demographics}

Table 1 outlines the demographics of the two groups, while table 2 outlines the diagnosis of the children with VI. There was a $67 \%$ response rate for the children with VI (24/36).

\section{QoL scores, demographic factors and factors of visual function as correlates or predictors of $\mathbf{0 o L}$}

Total QoL scores and all subscale scores in children with VI were statistically lower than in the age-matched comparison group (table 3, figure 1).

While not statistically significant, older children with VI $(n=15$, age 11-16) had poorer total OoL scores than their younger counterparts $(n=9$, age $5-10) \quad(76.30 \pm 27.28$ vs $87.50 \pm 20.88)$. The reverse is true when looking at the agematched comparison group, where the older children $(n=10)$ had better total QoL scores than their younger counterparts $(n=14)$ (118.05 \pm 10.23 vs $114.54 \pm 14.37)$.

Female parents completing the questionnaires (in children with VI ( $\mathrm{n}=17)$ and the age-matched comparison group $(\mathrm{n}=18)$ ) reported higher total QoL scores than male parents. This was statistically significant in the age-matched comparison group $(118.72 \pm 9.09$ vs $107.83 \pm 18.76 p<0.001)$.

The total QoL for children with VI was significantly correlated with distance logMAR VA (Spearman $\rho=-0.44)(p<0.05)$ and near $\log$ MAR VA (Spearman $\rho=-0.52)(p<0.01)$. Multiple regression of these factors against total QoL score revealed that $26.9 \%$ of the variability could be attributed to these variables. Thirty-eight per cent of the variability in total QoL score could

Table 1 Demographics of participants

\begin{tabular}{lllll}
\hline Group & Age (SD) & Sex & $\begin{array}{l}\text { Distance visual } \\
\text { acuity (logMAR) }\end{array}$ & $\begin{array}{l}\text { Near visual } \\
\text { acuity (logMAR) }\end{array}$ \\
\hline $\begin{array}{l}\text { Children with } \\
\text { visual impairment }(\mathrm{n}=24)\end{array}$ & $10.13 \pm 2.89$ & $18 \mathrm{M}$ & $0.59 \pm 0.28$ & $0.80 \pm 3.27$ \\
$\begin{array}{l}\text { Age-matched } \\
\text { comparison group }(\mathrm{n}=24)\end{array}$ & $9.83 \pm 2.81$ & $\begin{array}{l}6 \mathrm{~F} \\
18 \mathrm{M}\end{array}$ & At least 0.00 & Not measured \\
\hline
\end{tabular}


Table 2 Ophthalmic diagnoses in children with visual impairment

\begin{tabular}{ll}
\hline Description of eye condition & No of children \\
\hline Oculocutaneous albinism & 4 \\
Dislocation of lens & 1 \\
Retinal detachment with retinal break & 1 \\
Hereditary retinal dystrophy & 2 \\
Other retinal disorders in diseases & 1 \\
classified elsewhere (in this case Batten's & \\
disease) & \\
Optic atrophy & 3 \\
Nystagmus & 8 \\
Retinopathy of prematurity and & 2 \\
nystagmus & \\
Nystagmus and visual-field defect (in this \\
case homonymous hemianopia) \\
Congenital lens malformations
\end{tabular}

be attributed to distance logMAR VA, near logMAR VA and age. When assessed individually, distance logMAR VA contributed $24.6 \%$ to the variance, near logMAR VA $23.0 \%$ and age $0.27 \%$. Age was included in the regression equation, as there was an interesting trend relating to age and QoL (reported above). There were unfortunately insufficient numbers (due to unequal numbers in the groups) to look for correlations between stability of the eye condition, age at diagnosis and field loss with total QoL scores.

\section{DISCUSSION}

In this study, there was no control for the proxy effect. This is an accepted limitation. It has been reported ${ }^{2021}$ that parents of children with serious disability usually report a poorer QoL for their child than the child would report themselves and vice versa for healthy children. It is plausible that this study has served to increase the differences in scores between the groups. Future studies will need to control for this proxy effect by ensuring that they obtain only the child's views or separate the views of all contributors, being clear whether the views are their own or proxy for the child. Moreover, since we found that female proxys tend to report higher QoL than their male counterparts, consideration as to the sex of the proxy should be made. Cochrane et $a l^{17}$ recently demonstrated that the concerns expressed by support providers are different from that expressed by the child. Ensuring that all views are considered is of paramount importance when dealing with childhood VI to ensure that a complete assessment of the child's QoL is made. ${ }^{22}$ Having a specifically designed, age-appropriate questionnaire that the children can complete independently, such as the recently developed Cardiff Visual Ability Questionnaire (CVAOC) ${ }^{23}$ or the IVI_C, ${ }^{17}$ will help.
Limitations aside, our results highlight some important points to be considered by all those supporting children with VI.

The finding that the total and subscale QoL scores in children with VI were significantly lower $(p<0.001)$ than in the agematched comparison group requires careful consideration. When compared with the maximum QoL score of 125 , children with VI demonstrated a $35.6 \%$ reduction, and the age-matched comparison group a $7.2 \%$ reduction.

Although the LVOOL was not designed specifically for the paediatric population, the significant difference between children with VI and the age-matched comparison group serves to confirm the ability of the LVQOL to differentiate between these groups.

Why do children with VI have lower QoL scores than children in the age-matched comparison group, despite having undergone comprehensive habilitation? At this stage, we can only postulate on the reasons for this, as there have been no other studies looking at QoL in children with VI compared with an agematched comparison group. However, Wolffsohn ${ }^{19}$ also found that their adult patients, postrehabilitation, had lower QoL scores than those with normal vision.

Habilitation may be of great benefit to the child with VI but cannot fully restore QoL. These children throughout their lifetimes will continue to need to make modifications to their environment to improve their functioning, but these are unlikely to fully restore visual functioning and so will have a reduced QoL compared with their sighted peers. Future studies that include a control group for the type of habilitation will help us establish whether habilitation can be tailored to meet individual needs to improve individual QoL scores.

The effect of age on QoL in childhood VI is very important. In this study, older children with VI had poorer total QoL scores than their younger counterparts, and there was no significant difference in VA in either group. With increasing age, even when VA remains essentially unchanged, the demands made upon the visual system increase (eg, the requirement to read smaller print, to drive, etc). It could be postulated that an increasing inability to meet these demands would result in a poorer QoL. Future studies looking at QoL and childhood VI must take into consideration the effect of age on QoL.

It would be helpful, in a clinical setting, to be able to identify the test results that most accurately represent QoL so as to alert the clinician to patients with significantly reduced QoL.

In the present study, distance logMAR and near logMAR VA were significantly correlated with total $\mathrm{QoL} \quad(\mathrm{p}<0.05$ and $\mathrm{p}<0.01$, respectively). However, only $26.9 \%$ of the variability could be attributed to these variables. Thirty-eight per cent of the variability could be attributed to a combination of distance VA, near VA and age. This finding of a significant correlation but high unaccounted variance is in keeping with other studies. ${ }^{19} 24$

Table 3 Quality of Life ( $(\mathrm{OL})$ scores for children with visual impairment and age-matched comparison group

\begin{tabular}{llcc}
\hline Subscale & $\begin{array}{l}\text { OoL score children } \\
\text { with visual impairment }\end{array}$ & $\begin{array}{l}\text { OoL score age-matched } \\
\text { comparison group }\end{array}$ & Significance \\
\hline $\begin{array}{l}\text { Distance vision, mobility and lighting } \\
\text { (max 60) }\end{array}$ & $35.92 \pm 12.93$ & $54.98 \pm 9.37$ & $\mathrm{p}<0.001$ \\
Adjustment (max 20) & $14.98 \pm 3.61$ & $18.48 \pm 2.40$ & $\mathrm{p}<0.001$ \\
Reading and fine work (max 25) & $15.19 \pm 6.76$ & $23.17 \pm 3.14$ & $\mathrm{p}<0.001$ \\
Activities of daily living (max 20) & $14.32 \pm 4.34$ & $19.33 \pm 1.69$ & $\mathrm{p}<0.001$ \\
Total Low Vision Quality of Life & $80.50 \pm 25.21$ & $116.00 \pm 12.68$ & $\mathrm{p}<0.001$ \\
Questionnaire score (max 125) & & & \\
\hline
\end{tabular}




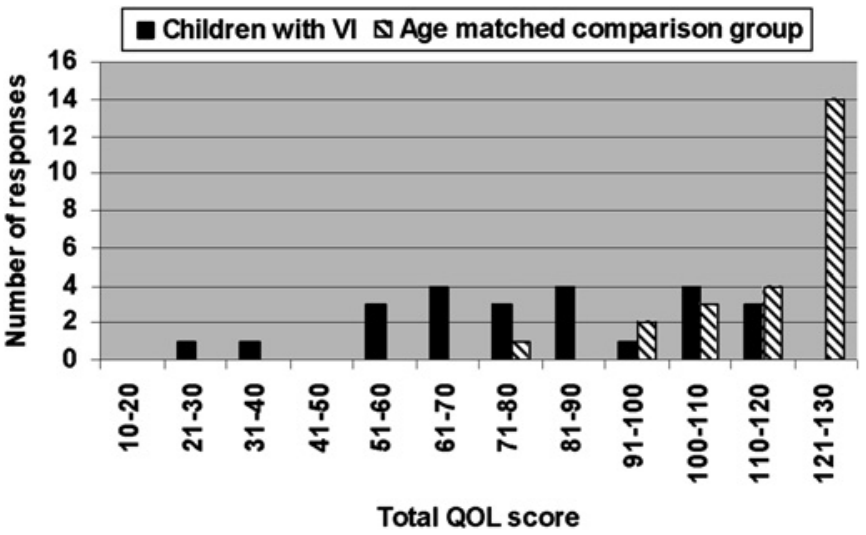

Figure 1 Number of responses with a given Quality of Life ( $\mathrm{OoL})$ score. VI, visual impairment.

Vision is a highly complex function, and so many clinical measures and non-clinical factors of visual function are likely to work together to influence the manner in which the VI affects the individual. Contrast sensitivity, reading speed and visual fields would have been obvious additional clinical measures to consider but are not recorded for all children attending the paediatric low vision clinic. Therefore, in this study, there were insufficient numbers to analyse these data. In childhood VI, it is important to consider the impact of wider non-clinical factors such as family socio-economic status, appropriateness and access to support provided by the child's school and other providers, peer and family relationships. It is plausible that these factors also play a part in predicting QoL. Therefore, it is unsurprising that the current study finds that, at best, $38 \%$ of the variance can be accounted for. Future studies will need to look at the additional clinical and non-clinical factors that combine to predict QoL scores in children with VI.

By better understanding QoL in childhood VI, and the factors that can be modified to affect QoL, changes to habilitation services can be made to better support and personalise the care provided for these children and families. Care providers can then work to eliminate the postcode lottery of paediatric low-vision services in the UK and promote good-quality, uniform, costeffective paediatric low-vision services.

Acknowledgements The authors would like to thank the Optometry Department at Oxford Eye Hospital for their support and the two reviewers for their comments.

Competing interests None

Patient consent Obtained from the parents.

Ethics approval Ethics approval was provided by the Oxfordshire REC B.

Provenance and peer review Not commissioned; externally peer reviewed.

\section{REFERENCES}

1. Rahi JS, Cable N. Severe visual impairment and blindness in children in the UK Lancet 2003;362:1359-65.

2. Charles N. Estimates of the number of older people with a visual impairment in the UK. Br J Vis Impair 2007;25:199-215.

3. Gilbert CE, Foster A. Childhood blindness in the context of VISION 2020 — the right to sight. Bull World Health Organ 2001;79:227-32.

4. Fielder A, Boulton M, Clegg S, et al. A charter for families of young children with visual impairments. http://www.rnib.org.uk/livingwithsightloss/Documents/charter. doc (accessed 3 May 2010).

5. RNIB Complexity of prevalence stats for children. http://www.rnib.org.uk/Search/ Pages/results.aspx?k=childhood\%20visual\%20impairment (accessed 3 May 2010).

6. The Information Centre for Health and Social Care. People Registered as Blind and Partially Sighted (Triennial) 2006 England. http://www.ic.nhs.uk/statistics-anddata-collections/social-care/adult-social-care-information/people-registered-as-blindand-partially-sighted-triennial-2006-england (accessed 4 June 2009).

7. Flanagan NM, Jackson AJ, Hill AE. Visual Impairment in childhood: insights from a community based survey. Child Care Health Dev 2003;29:493-9.

8. Anon. Low Vision Services Consensus Group Recommendations for Future Service Delivery in the Uk. London: Royal National Institute for the Blind, 1999.

9. Low Vision Working Group Recommended Standards for Low Vision Services. 2007 http://www.eyecare.nhs.uk/uploads/Recommendedstandardsforlowvisionservices. doc (accessed 3 May 2010).

10. Kelley $\mathbf{P}$, Sanspree M, Davidson R. Vision Impairment in children and youth. In: Silverstone BLM, Rosenthal B, Faye E, eds. Vision Impairment and Vision Rehabilitation. Vol. 2. New York: Oxford University Press, 2000:1137-51.

11. RNIB Education provision for blind and partially sighted children and young people in England 2007. http://www.rnib.org.uk/aboutus/Research/reports/edemp/Documents/ NFER GB Report.doc (accessed 3 May 2010).

12. Pilling $\mathbf{R} \overline{\mathbf{F}}$, Thompson JR, Gottlob I. Social and visual function in nystagmus. $\mathrm{Br} \mathrm{J}$ Ophthalmol 2005;89:1278-81.

13. Chak MH, Rahi JS; British Congenital Cataract Interest Group. The quality of life of children with congenital cataract: findings of the British Congenital Cataract Study. $\mathrm{Br}$ J Ophthalmol 2007;91:922-6.

14. Boulton M, Haines L, Smyth D, et al. Health-related quality of life of children with vision impairment or blindness. Dev Med Child Neuro 2006:48:656-61.

15. Felius J, Stager DR Sr, Berry PM, et al. Development of an instrument to assess vision-related quality of life in young children. Am J Ophthalmol 2004;138:362-72.

16. Gothwal VK, Lovie-Kitchin JE, Nutheti R. The development of the LV PrasadFunctional Vision Questionnaire: a measure of functional vision performance of visually impaired children. Invest Ophthalmol Vis Sci 2003:44:4131-9.

17. Cochrane G, Lamoureux E, Keeffe J. Defining the content for a new quality of life questionnaire for students with low vision (the Impact of Vision Impairment on Children: IVI C). Ophthalmic Epidemiol 2008;15:114-20.

18. Birch EE, Cheng CS, Felius J. Validity and reliability of the Children's Visual Function Questionnaire. J Aapos 2007;11:473-9.

19. Wolffsohn JS, Cochrane AL. Design of the low vision quality-of-life questionnaire (LVOOL) and measuring the outcome of low-vision rehabilitation. Am J Ophthalmol 2000;130:793-802

20. Russell KM, Hudson M, Long M, et al. Assessment of health related quality of life in children with cancer: consistency and agreement between parent and child reports. Cancer 2006;106:2267-74.

21. Odom J, Hix C, Cohen $\mathrm{S}$, et al. Assessing quality of life in school-aged low vision patients: a comparison of child and proxy assessments. Invest Ophthalmol Vis Sci 2004;45:E-abstract 5003.

22. White- Koning $\mathbf{M}$, Grandjean $\mathrm{H}$, Colver $\mathrm{A}$, et al. Parent and professional reports of the quality of life of children with cerebral palsy and associated intellectual impairment. Dev Med Child Neurol 2008;50:618-24.

23. Khadka J, Ryan B, Margrain T, et al. Development of the 25-item Cardiff Visual Ability Questionnaire for Children (CVAOC). Br J Ophthalmol 2010;94:730-5.

24. McClure ME, Hart PM, Jackson AJ. Macular degeneration: do conventional measurements of impaired visual function equate with visual disability? $\mathrm{Br} \mathrm{J}$ Ophthalmology 2000;84:244-50. 